\title{
Corporalidad y ciudadanía en México: Don Justo de José Gómez Robleda (1940-1950)
}

\section{Corporality and Citizenship in Mexico: Don Justo de José Gómez Robleda (1940-1950)}

http://dx.doi.org/10.17981/cultedusoc.12.2.2021.08

Recibido: 15 de septiembre de 2020 Aceptado: 20 de enero de 2021 Publicado: 1 de julio de 2021.

Gustavo Adolfo Enríquez-Gutiérrez

Universidad Pedagógica Nacional. Morelos (México)

gusen68@hotmail.com

Para citar este artículo:

Enríquez-Gutiérrez, G. (2021). Corporalidad y ciudadanía en México: Don Justo de José Gómez Robleda (1940-1950). Cultura, Educación y Sociedad, 12(2), 131-146. DOI: http://dx.doi.org/10.17981/cultedusoc.12.2.2021.08

\section{Resumen}

El texto aborda parte de la investigación sobre José Gómez Robleda de 1940 a 1950 en México sobre el cuerpo, la ciudadanía y la educación. El análisis interpreta la relación entre cuerpo y ciudadanía a través de la novela: Don Justo de José Gómez Robleda. Metodológicamente, se vincula el cuerpo y la ciudadanía como contenidos centrales de análisis a través de una investigación cualitativa, histórica y documental apoyada en fuentes primarias y secundarias. El trabajo coloca la importancia del cuerpo a través del biopoder en Foucault y el análisis de Michel de Certeau sobre los aparatos de su encarnación. El entramado analítico comprende la biotipología de José Gómez Robleda y la forma en que definió la corporalidad en la civilidad, la ciudadanía y la escuela. Las conclusiones principales del texto apuntan: a) al cuerpo como eje rector en la conformación ciudadana mexicana a mediados del siglo XX; b) la explicación racial corporal de la modernidad y la actividad laboral como ejes de la ciudadanía mexicana de mediados del siglo XX, en lo individual y social.

Palabras clave: Modernidad; ciudadanía; progreso; biometría; educación ciudadana.

\section{Abstract}

The text approaches part of José Gómez Robleda's investigation on the body, citizenship and education, from 1940 to 1950, in Mexico. The analysis interprets the relationship between body and citizenship through the novel Don Justo, by José Gómez Robleda. Methodologically, the body and citizenship are linked as the core content of analysis through a qualitative, historic, and documental investigation in primary and secondary sources. The work positions the body's importance through Michel Foucault's biopower and Michel de Certeau's analysis of its incarnation apparatus. The analytical framework comprehends the biotypology of José Gómez Robleda and the way it defined the corporality within civility, citizenship, and the school. The main conclusions of the text point at a) the body as the guiding axis of the Mexican citizenship formation in the mid-twentieth century; b) The racial corporal explanation of modernity and the labor activity as the axis of twentieth-century Mexican citizenship, individually and socially.

Keywords: Modernity; citizenship; progress; biometry; citizen education. 


\section{INTRODUCCIÓN}

La novela Don Justo (1946) de José Gómez Robleda ${ }^{1}$, formó parte de la narrativa social sobre la formación ciudadana de los escolares mexicanos. La investigación se ubica en la "Unidad Nacional", en los sexenios presidenciales de Manuel Ávila Camacho (1940-1946), y Miguel Alemán Valdés (1946-1952). Este periodo, significó un cambio del proyecto educativo rural y comunitario posrevolucionario, por otro, urbano desde la unidad nacional (Lazarín,1996).

La unidad nacional partió de la pedagogía del amor y la formación moral de los escolares (Vejar, 1944). Esto significó educar la moral del cuerpo de los escolares mexicanos en lo individual, familiar y comunitario desde una sola nación (Reyes, 2005). Las políticas educativas buscaron la normalización moral, sanitaria e higiénica en hombres y mujeres (Reggiani, 2019; Suárez, 2005; 1999; Suárez y Ruíz, 2001).

Estos criterios políticos influyeron en la alimentación, el cuidado físico, la higiene y en la formación de hombres y mujeres (Melchor, 2018; Reggiani, 2019; Saade, 2004; Stern, 2002; 2000; Granjas, 2011). Estas políticas definieron la normalidad de los cuerpos, de acuerdo con Gómez, en escolares proletarios (1937), criminales (1939), deportistas (1940), indígenas (1943, 1948 y 1961) y clase media (1948). Gómez fue un operador de las políticas del gobierno; un difusor de sus ideas educativas a través de la novela que circuló en las escuelas primarias mexicanas en 1947 (De la Peza y Corona, 2000). Don Justo fue leído por escolares, y docentes como una imagen literaria y moral sobre lo educado, moderno y civilizado.

Las lecciones de la novela de Don Justo expresaron la verdad científica, la conducta moral, la higiene de los escolares y la formación del mexicano (Gómez, 1946). Don Justo apuntó, hacia la modernidad escolar a través de lecciones sobre la vida, la biografía de científicos, artistas y filósofos; además explicó los problemas científicos y sociales. La modernidad escolar buscó formar al hombre medio: "expresión perfecta y máxima del individuo" e imagen del mexicano (Gómez, 1947) y siguiendo a Vejar (1944), Secretario de Educación del momento: “... el patrón o imagen abstracta del tipo nacional en vista de la teoría del hombre medio o normotipo, según el cual, es el representativo de una nacionalidad..." (1944, p. 89).

El modelo de formación en Don Justo articuló tanto la pedagogía del buen ciudadano, como los cánones científicos imperantes. En Don Justo se despliegan lecciones pedagógicas sobre la ciudadanía, el cuerpo como su portador y la escolaridad como rasgo particular de la mexicanidad. Bajo la enmienda: "En la escuela hay que aprender a ser felices", se normalizaron los cuerpos en los escolares y el docente fue modelo de formación ciudadana (Gómez, 1946).

\footnotetext{
1 José Gómez Robleda (1904-1987), autor de Don Justo, fue investigador y funcionario público del gobierno mexicano. Su figura permite comprender la mediación política, académica y científica tanto en la Secretaría de Educación Pública (SEP) como en la Universidad Nacional Autónoma de México (UNAM). Su investigación se desarrolló desde la biotipología en la dimensión social (1972), cultural (1948), física (1940), biológica (1947) y educativa (1946). En la educación fue promotor de la formación ciudadana infantil a través de valores cívicos y morales asentados en la ciencia, la explicación del mundo y la vida, así como, en el equilibrio psico-físico del cuerpo.
} 


\section{Fundamentos TeóRICos}

Don Justo permite ubicar la escritura sobre el maestro mexicano en la ficción literaria. Una historia sobre el cuerpo al "querer saber y producir" prácticas sobre la escuela. Un relato donde se manipula, conforma y analiza la escuela, las clases escolares y la relaciones del maestro con el grupo. Un relato sobre lo escolar en el lenguaje escrito al "decir, creer y hacer" la escuela (De Certeau, 2008; 2000).

En esta ficción, el otro se insinuó, y su saber apareció como estudiante, maestro; niño, niña; trabajador, profesionista, científico o político. La ficción fue un puente para pensar, articular lo posible, reconocer la realidad de aquello ocurrido tanto interna como externamente. Lo interno y externo tienen la misma consecuencia al interpretar lo qué se dice, cómo se dice y cuándo se dice. Un discurso más próximo a lo real desde un cuerpo definido por los personajes, circunscrito, articulado por el escenario escolar, donde los papeles son el centro de la teatralidad narrada en y desde Don Justo (De Certeau, 2008; 2000).

El cuerpo narrado condensó significaciones sobre el ordenamiento social, escolar e individual (Enríquez y Cruz, 2020; Enríquez y Sandoval, 2018). El cuerpo pasó de ser un ente social, hacia su encarnación individual como mujer o hombre desde los atributos de lo mexicano. El cuerpo individual a lo largo del siglo XX, mostró su valor, belleza e indicó su actividad laboral (Le Breton, 1995; Vigarello, 2005).

La corporalidad mexicana se expresó de diversas maneras, pero, mostró su especificidad en el médico, el artista, el campesino o el obrero, al mismo tiempo, exhibió al empresario, al político, al intelectual, al profesionista, al trabajador o al burócrata; de este modo, reflejó al indígena, la mujer, el anormal, el anciano, el enfermo, el delgado, el capaz o el bello. El cuerpo de mujeres y hombres formaron los rasgos individuales de la identidad, y fueron los portadores sociales de la ciudadanía, el género y de la actividad profesional, laboral o artística (Acevedo y López, 2012; Piccato, 2012).

El cuerpo dio valía, seguridad y colocó a cada uno en un espacio, en un tiempo, donde el significado de la(s) persona(s) denotó, y connotó su papel en el mundo cotidiano en que vivió. El guion representado en la trama de significados manifestado en los escenarios institucionales (Fast, 1998; Guzmán, 2008; Muñiz, 2002). El cuerpo afirmó, negó o confirmó su pertenencia a estas significaciones sociales, por ejemplo; Lázaro Cárdenas, Diego Rivera, María Félix, José Vasconcelos o Frida Kahlo establecieron sentidos corporales diferentes en lo social, cultural y político condensando estos significados corporales a seguir en hombres y mujeres mestizos en la nación mexicana.

\section{Metodología}

La investigación partió de la pregunta: ¿Cuáles son las normas morales y rasgos corporales sobre la ciudadanía escolar indicadas por José Gómez Robleda en la novela de Don Justo? Desde esta pregunta, se articularon la ciudadanía y el cuerpo a fin de comprender estos conceptos como contenidos centrales de indagación. La investigación tiene un corte cualitativo y documental a través de la recolección de datos en fuentes primarias y del análisis del texto en su contexto histórico. La ciudadanía sugerida en las normas 
y preceptos morales asignados al cuerpo de un buen mexicano (Acevedo y López, 2012; López, 2009; Piccato, 2012). El cuerpo enmarcado socio-históricamente, encarnado y teatralizado en prácticas de poder (De Certeau, 1982; Foucault, 2007; 1980). El biopoder a través de estrategias político-sociales (biopolítica), y su intervención psicopedagógica (anatomopolítica) en dispositivos disciplinarios de corporización de la ciudadanía en el hombre medio (Foucault, 2007; 1980). La biopolítica, en el caso mexicano, se inscribió en la constitución, en las leyes y los reglamentos administrados en las instituciones gubernamentales del país y de manera importante en las instituciones escolares (Aréchiga, 2007; Granjas, 2011).

\section{Resultados}

A partir de la pregunta y del análisis del texto, se interpreta la ciudadanía escolar en tres sentidos: 1) Ciudadanía corporal en José Gómez Robleda, 2) La ciudadanía corporal en Don Justo y 3) La corporalidad escolar ciudadana en Don Justo. A continuación se describen estos resultados.

\section{La ciudadanía corporal en José Gómez Robleda}

En la unidad nacional el gobierno partió de una situación conflictiva entre los grupos políticos, los intelectuales, la iglesia y los lideres sociales sobre el lugar de la cultura, los problemas sociales, políticos, educativos, económicos y el desarrollo nacional. Esta situación llevó a la presidencia al control del proyecto nacional. En el ámbito internacional, debido a la guerra mundial, el gobierno se enfocó a establecer una relación más estrecha con los Estados Unidos de América (Loaeza, 2013a; 2013b; Medina, 1974).

Este marco favoreció que el cine, la música, la pintura, la literatura, la alimentación, la vivienda y la música mostrarán la forma de ser mexicanos y mexicanas a través de personajes como el charro, la china poblana, el catrín, la dama, la mujer fatal y el peladito (Domínguez, 2011; González, 2009; Tuñón, 1994; Sosenski y López, 2015). Los intelectuales e investigadores mexicanos buscaron puentes entre la tradición nacional, católica y rural; reflexionaron sobre la historia criolla, indígena y mestiza a fin de vincular estos aspectos con el mundo occidental sin perder lo nacional (Illades y Suárez, 2012).

El cine apuntó la complejidad de la vida urbana, por ejemplo: "Del rancho a la ciudad" Anda, 1942; "Soy puro mexicano" Fernández, 1942 y "Campeón sin corona" Galindo, 1945. La nueva vida familiar mexicana se presentó en: "Nosotros los pobres" Rodríguez, 1947 o "Una familia de tantas" Galindo, 1948. En la música, Moncayo a través de su concierto "Huapango" de 1941 dio cuenta de esta fusión entre tradición y modernidad al igual que Salvador Contreras, Carlos Chávez, Candelario Huízar y Silvestre Revueltas.

En el tenor académico los problemas sobre México implicaron su discusión en varios ámbitos y lo mexicano como problema fue una temática analizada. Desde el derecho, la teoría de la defensa en Quiroz Cuarón investigó la criminalidad del mexicano de esta 
época ${ }^{2}$. La antropología física del mexicano en los trababajos de Ada D’Aloja, Juan Comas y Santiago Genovés en la Escuela Nacional de Antropología e Historia en 1942 (Faulhaber, 2003; Matos, 2001) ${ }^{3}$.

La sociología del mexicano con los trabajos de Lucio Mendieta y Nuñez primer director tanto de la Revista Mexicana de Sociología en 1939, como del Instituto de Investigaciones Sociales de la UNAM en el mismo año (Olvera, 2016) ${ }^{4}$. En psiquiatria con las investigaciones de 1933 a 1952 de Manuel Guevara Oropeza, Samuel Ramírez Moreno, Leopoldo Salazar Viniegra, Guillermo Dávila, Martín Ramos Contreras, Raúl González Enríquez, Edmundo Buentello, Alfonso Millán y Mario Fuentes Delgado (De la Fuente y Heize, 2014) $)^{5}$.

Lo mexicano y la mexicanidad, su psicología, sus problemas y la raza fueron analizados por Ramos en 1943, Paz en 1950, Villoro en 1950 y Reyes en 1952 (Illades y Suárez, 2012). La cultura, la educación y el trabajo práctico formaron la triada del progreso social, económico y educativo del país (Gudiño-Cejudo, Magaña-Valladares y Hernández-Ávila, 2013). La educación fue vía de progreso, modernidad y civilidad a través de la unidad en lo nacional, en lo internacional con la educación fundamental (Lazarín, 1996; Rangel, 2006).

La mexicanidad desde la mirada educativa partió de valores científicos, capacidades técnicas, e industriales desde la "pedagogía del amor". Una pedagogía de unificación individual, familiar y nacional. La constitución en su artículo 3ero sobre la educación la indicó como "laica, obligatoria y gratuita" (Arredondo y González, 2014; Ornelas, 1995; Ortiz-Cirilo, 2015). Pedagogía del amor en el mexicano promedio como visión de unidad nacional (Vejar, 1944).

En este marco, José Gómez Robleda, investigó la constitución psicofísica de los mexicanos. Su meta fue diseñar planes educativos, e intervenir en la salud corporal. La ciudadanía biotipológicamente, partió del hombre medio: "como adaptable al ambiente local desde un máximo equilibrio funcional entre todas sus partes" (Gómez, 1947). La medición corporal buscó la armonía entre longitud, anchura, igualdad de volumen, rendimiento en velocidad y resistencia. La armonía de medidas, la adaptabilidad, y la salud física, proporcionaron el ideal de ciudadanía a través del hombre medio (Gómez, 1940; 1948).

La idea de hombre medio en la escuela tuvo como antecedente, "Características biológicas de los escolares proletarios" en 1937. Estudio de 120 estudiantes (70 niños y 50 niñas) en la escuela primaria: "Ramón López Velarde", en la colonia obrera de la Ciudad de México. El estudio indagó las características somáticas, y funcionales de los escolares. Investigación realizada por el Instituto Nacional de Psicopedagogía de la Secretaría de Educación Pública (SEP), del gobierno mexicano (Gómez, 1937).

\footnotetext{
2 Alfonso Quiroz fue discípulo de José Gómez Robleda. En 1939 publicaron: "Tendencias y ritmo de la criminalidad" en México, D.F. Quiroz participó en varias de las investigaciones de Gómez, por ejemplo, en 1937 sobre escolares proletarios; 1943 Tarascos; 1949 Zapotecos y 1961 Otomíes.

3 Gómez colaboró con Ada D’Aloja en 1947 en "Biotipología", en 1959 en "La familia y la casa", y en 1961 "Estudio biotipológico sobre los otomíes" (Gómez, 1947; Gómez, 1959; Gómez, 1961).

4 Colaboró con Lucio Mendieta y Núñez en su investigación sobre "Los zapotecos: monografía histórica y etnografía y estudio económico de1949".

5 En 1933, Gómez publicó un cuento "Esquizofrénico" donde escribe esta conducta a través del relato literario que tuvo como antecedente su incursión como médico en 1920 en la Castañeda.
} 
La escuela primaria "Ramón López Velarde" mostró la escasa higiene y exigua salud de los escolares proletarios (Gómez, 1937). La mala higiene, la pésima construcción del inmueble, y las precarias condiciones de iluminación reiteraron el problema de salud de los escolares proletarios (Gómez, 1937). La mirada biotipológica partió del mejoramiento individual, y social a través de la higiene a fin de asegurar la ciudadanización.

La interpretación de Gómez, sobre los escolares fue que el medio inadecuado ocasionó problemas en su salud física, moral y social. Estos resultados sociales, somáticos y funcionales de escolares proletarios, además de su trabajos sobre criminalidad, deportistas e indígenas le llevarían a establecer la imagen del mexicano y su idea de hombre promedio (Gómez, 1937; 1939; 1940; 1943; 1947; 1948).

\section{La corporalidad ciudadana en Don Justo}

La imagen de la mexicanidad, de esta época, se expresó y difundió en las formas de portar el cuerpo. El cine, la radio, la pintura, las artes, los oficios, los trabajos y las profesiones lo encarnaron (Muñiz, 2002; López, 2009). La patria como unidad, lo expresó, Ramón López Velarde: "Patria: tu superficie es el maíz, tus minas el palacio del Rey de Oros, y tu cielo, las garzas en desliz y el relámpago verde de los loros".

El presidente, Manuel Ávila Camacho, lo indicó: "Las posibilidades de perduración de un país están en razón directa de su unidad y para afianzar su unidad el problema fundamental es la educación. Pero una educación no limitada a desalfabetizar a los ignorantes arrancándolos a la oscuridad de su cuna para hundirlos en las tinieblas, tal vez peores, del automatismo mental primario, en el que se reclutan a los ineficaces" (Vejar, 1944, p. 49). La unidad nacional estuvo vinculada a rasgos físicos, aptitudes intelectuales y psicológicas (Gómez, 1937; 1940; 1946; 1947; 1948). La escuela formó mexicanos en la civilidad, la cultura y la unidad nacional (Rangel, 2006).

Los cuerpos en Don Justo encarnaron la ley de la escuela urbana mexicana. El cuerpo de Don Justo mostró la civilidad y ciudadanía como: "muy limpio, pálido y esbelto" (Gómez, 1946, p. 7). Limpieza, delgadez y tono blanco en la piel, se complementaron con: "inteligente, observador y servil" (Gómez, 1946). En "Corazón de niño" de Alejandro Galindo en 1939, y "Río escondido" de Emilio "El indio Fernández" en 1948, mostraron una parte de esta corporalidad ciudadana escolar. Estos relatos presentaron al maestro o la maestra, entregados al trabajo, cultos, observadores, formadores de individuos y apreciados por la comunidad. Las palabras del profesor Perbono, interpretado por Domingo Soler en la película: "Corazón de niño", dieron cuenta de la narrativa sobre el maestro mexicano:

Muchachos, hoy damos comienzo al año escolar, quiero recordarles que esta escuela está orgullosa de los hombres que ha formado, que durante más de un siglo han salido de aquí hombres de ciencia, artistas, grandes maestros, profesionistas civiles, en fin, hombres que dan honra a la patria, ustedes tienen el deber de continuar y acrecentar esta tradición gloriosa, de conservar el honor de la escuela de ser leales a la institución, ¿saben cómo se logra esto?, con buen comportamiento, respetando a sus maestros, generosidad en el compañero y, sobre todo, estudio, mucho estudio, tengan eso presente (Gómez y García, 2018, p. 1584). 
Estos atributos, se complementaron con los de Don Justo: "delgadez y blancura"; aunados a la "inteligencia, observación y servicio". Modelo de civilidad corporal mexicana a mediados del siglo XX. En los alumnos, se mezcló clasismo social, anhelos morales, estereotipos y condiciones económicas. Por ejemplo, Roberto fue: “... un niño delicado, débil y adinerado" (Gómez, 1946). Estos aspectos dieron cuenta tanto de la fortaleza física como de la delicadeza en la ciudadanía. La constitución corporal indicó el rango social de la persona, al cotejarla con el tipo medio estudiado por Gómez (1948).

Vicente, amigo de Roberto, fue descrito: “... es hijo de un peluquero, servicial, muy aplicado, y de familia numerosa”(Gómez, 1946). Estas particularidades más los atributos físicos del padre: "gordo, muy reposado y amable conversador" (Gómez, 1946). Dieron cuenta del perfil corporal y de las capacidades del trabajador: "servicial y aplicado" y sobre su salud marcaron su "obesidad" (Gómez, 1937).

El intendente, fue un "viejo gruñón, de larga estatura, de gran fuerza física, tiene cerca de 70 años, tiene el cabello cano, es de tez morena y usa anteojos" (Gómez, 1946). La descripción, dejó entrever la estructura escolar diferencial: el profesor, el intendente, el estudiante, y el hijo de un obrero. En Don Justo apareció el médico: "tenía el pelo entrecano y no muy abundante, echado hacia atrás; sus facciones eran muy firmes: ojos pequeños, pero muy vivos; nariz afilada, boca chica y bigote recortado a la inglesa." [Las cursivas son nuestras] (Gómez, 1946, p. 307).

El médico correspondió a un biotipo corporal de clase media con atributos de civilidad e higiene. La indumentaria transmitió una imagen social de "seguridad, dominio, y experiencia". Las particularidades físicas denotaron una visión occidental de la profesión, y las psicológicas, connotaron a la inteligencia como epítome de la especialización. Otro perfil profesional que sugirió el texto fue el del científico:

Era de baja estatura, fornido, moreno y de muy inteligentes ojos negros que se movían con rapidez detrás de sus anteojos. Su pelo era negro, lacio y algo rebelde; peinado de raya a un lado, el mechón principal se levantaba, del lado opuesto. Sus dientes eran parejos, pero muy firmes, su nariz achatada y sus manos pequeñas, bastante nerviosas [Las cursivas son nuestras] (Gómez, 1946, pp. 294-295).

El científico fue representado por Don Eliseo, amigo de Don Justo, consultado por él y sus alumnos sobre temas científicos. Don Eliseo fue un hombre inteligente, moreno y de baja estatura. Mestizo de clase media similar al médico. Su ingenio, su capacidad de observación, y sencillez indicaron el lugar del saber científico.

Esta serie de perfiles dieron cuenta de un fragmento de la corporalidad sobre los imaginarios sociales de civilidad y ciudadanía. Corporalidad ciudadana apoyada en la escuela como lugar formativo, y al maestro, mediador de estas micropolíticas corporales. La higiene, el mestizaje y la apariencia física; apuntaron a la acumulación de rasgos corporales de la ciudadanía. Elementos corporales vistos, etiquetados y mostrados desde un lugar del imaginario del mexicano promedio de clase media, y de una mirada de la ciudadanía mestiza de mediados del siglo XX en México. 


\section{La corporalidad escolar ciudadana en Don Justo}

El cuerpo en Don Justo, fue uno de los referentes sobre la mexicanidad de mediados del siglo XX. Gómez Robleda usó estándares científicos, sociales y morales de biotipos. El marco de la modernidad del cuerpo partió de estrategias educativas encarnadas en la institución escolar imaginada. Este esquema, buscó formar al hombre medio. Don Justo simbolizó estos rasgos en él y en los personajes de la novela: científicos, hombres comunes, mujeres, trabajadores, delincuentes e indígenas.

En la imagen del mexicano Gómez (1948), elaboró su concepto de "hombre promedio" o "estándar", como "hombre de clase media, mestizo, citadino, productivo, inteligente y heterosexual". En su investigación sobre los Tarascos (Gómez, 1943), desarrolló las medidas de la normalidad corporal mexicana. Estableció un rango de evaluación corporal de tipos simples, mixtos, biotipos y criminales. En Don Justo, se describió a los indígenas como:

Los indios caminan por el mundo siempre atentos a cuanto ocurre a su alrededor; desde su interior, desconocido, asoma un espíritu vigilante para contemplar la esplendorosa realidad del Universo. Las duras faenas diarias, el inacabable ganarse el pan trabajosamente entre piedras y tierra, el eterno luchar contra la naturaleza, persistentemente fija y dura, ha encallecido sus manos que fueron ágiles para tocar sensualmente; entre el hombre y el mundo se interpone una sensibilidad que ahora les impide mover los dedos con soltura, como lo hicieron antes, para dejar construida y tangible la expresión de las más sublimes emociones. La cara triste y el gesto expectante de nuestros indios vivos atestiguan la diversidad del medio en el que viven. [Las cursivas son nuestras] (Gómez, 1946, p. 391).

La expresión "cara triste" y "gesto expectante" del indio se contrapuso con la del mexicano mestizo de clase media: "alegre, divertido e inteligente" (Enríquez y Sandoval, 2018). El indígena fue observador, trabajador, triste y expectante. Corporalmente, la faena diaria, la lucha contra la naturaleza, encallecieron sus manos; obligándolos adecuarse a una sociedad, que poco requiere el toque sensual, y la construcción sublime de emociones. En este tenor, Gómez (1946) expresó en Don Justo:

En conjunto los indios -continuó nuestro profesor-, como invencible ejército del porvenir, son admirables por su resistencia que no tiene punto de comparación y por su increíble virtud de saberse adaptar para dominar el empuje hostil del medio seco y polvoso, con piedras duras, anchos valles, minas profundas, enormes mares, tormentas, ciclones, terremotos y epidemias y calamidades sociales y aun con incomprensibles hombres blancos y mestizos. Tanto trabajar cansa a padres e hijos, tanto fatigarse y mal comer los ha llevado al alcoholismo que les repara las fuerza y les hace tolerable a un mundo ruin [Las cursivas son nuestras] (p. 391).

El vínculo conceptual indígena-pobreza-alcoholismo, generó la intoxicación constante. La constitución física estuvo marcada por trabajo exhaustivo, precaria alimentación y bajo estatus social (Gómez, 1937). La segregación social fue sustentada en el pasado, y su aparente debilidad intelectual (Gómez, 1946). Los indios aparecieron como desajustados a los cánones científicos de la época; conservando sus propios sistemas de conocimiento, tradiciones y costumbres (Gómez, 1946). 
Otro tema de las lecciones escolares, en Don Justo, fue el vicio, y la enfermedad. El alcoholismo como enfermedad partió de los padecimientos mentales y la nutrición. El alcohólico fue descrito como un enfermo físico y mental, incapaz de curarse con medicamento. Por ello, resultó necesario encaminarlo al canon del buen ciudadano (Gómez, 1946):

Se me ocurre una pregunta, don Justo: ¿es lo mismo enfermedad que vicio?

- Muy bien pensado, Aurelio. Desde el punto de vista de la medicina, los vicios son enfermedades, generalmente padecimientos mentales que después se complican por las consecuencias de la intoxicación. Los alcohólicos crónicos, tan repugnantes comúnmente, al principio sólo fueron individuos amargados o desilusionados de la vida: una gran decepción, alguna desgracia o motivos de infelicidad, pueden ser el comienzo del hábito del alcoholismo. Decir, despectivamente, de estos desafortunados que son viciosos, equivale a no haberlos comprendido; estos hábitos no se curan ni con medicinas ni, menos aún, con amenazas o prohibiciones [Las cursivas son nuestras] (p. 238).

El alcoholismo, en Don Justo, fue una asociación entre enfermedad y vicio, derivado de un inadecuado modo de vivir. El alcohólico fue el contraste de la ciudadanía. La intoxicación como amenaza a la salud moderna, y a la ciudadanía corporal. El alcoholismo fue vicio tóxico, enfermedad del espíritu, y padecimiento mental.

La intoxicación, en Gómez, fue de tres tipos: exógena (alimentación, agua insalubre, alcoholismo); endógena (causada por la fatiga en el trabajo); e intoxicación moral (diversiones procaces y fanatismo) (Gómez, 1937). Insistió en una buena alimentación con vitaminas, aminoácidos, trabajo adecuado y moral moderna (Quiroz, Gómez y Argüelles, 1939). Gómez apreció al profesor como un mediador pedagógico y formador de ciudadanos:

Un maestro — decía - vive apuradamente, porque debe entregar a sus discípulos, día tras día, la última palabra del pensamiento humano. Cada año se sientan frente a nosotros, niños alegres y tristes, agitados y tranquilos, ricos y pobres, que llegan siempre a la escuela con ojos muy vivos que alumbra la llama interior de la vida que empieza. Son miles de caras diferentes por las que asoma el mismo océano del espíritu, uniforme y diverso, que guarda en la profundidad los gérmenes de todos los misterios y que refleja, en la superficie, la solemnidad del cielo. Nuestros niños, que llegan eternamente iguales, son en contraste de sus maestros, cada instante más viejos, más distintos, más extraños al mundo, más preocupados, más atormentados por las dudas y, también, más solos [Las cursivas son nuestras] (1946, p. 149).

La relación entre el maestro y los alumnos fue determinante en la formación corporal de la ciudadanía escolar. Enseñanza dada en el comportamiento, al explicar y formar escolares instruidos, mexicanos trabajadores y ciudadanos modernos. El buen docente: "entregó la última palabra del pensamiento humano" y buscó responder a las dudas del océano del espíritu. Tales actitudes se manifestaron al anteponer su realización personal por el trabajo. En este sentido, las palabras del director de la escuela, tras la muerte del profesor lo mostraron: 
Tengo que cumplir el amargo deber de comunicar a ustedes, con profunda pena, que nuestro querido don Justo ha dejado de existir. Dedicó toda su vida a la noble profesión de la enseñanza y murió, ejemplarmente, frente a su mesa de trabajo. El señor Ministro, que fue discípulo suyo, ha dispuesto que su cuerpo permanezca entre nosotros antes de que ocupe su lugar definitivo y le ha concedido el honor de ser cubierto con la Bandera Nacional para que comprendamos todos que el Gobierno de la República lo considera como un hijo predilecto de la Patria. [Las cursivas son nuestras] (p. 416).

Las características del maestro fueron: "profesionalismo, vocación y enseñanza” (Gómez, 1946). Estas características fueron enlazadas con el respeto a las autoridades, al gobierno, y apego al proyecto nacional. El docente representó a la patria ante la familia. Fue un modelo de civilidad en el grupo escolar, y un trabajador al servicio del Estado. La autoridad del docente permitió formar la corporalidad ciudadana desde un modelo de civilidad social. En este sentido, Gómez (1946) destacó este modelaje a través de Don Justo usando la higiene como su portador:

Siempre he procurado presentarme limpio por higiene y por educación. La limpieza es una de las formas mejores de decencia y la limpieza espiritual más que decencia, es un homenaje a la dignidad humana. La suciedad es una ofensa, significa desprecio a la propia persona; casi es una injuria dirigida a nuestros semejantes". [Las cursivas son nuestras] (pp. 91-92).

Don Justo manifestó la "decencia y dignidad". Valores de educación, modernidad y civilidad personal. Por el contrario, la suciedad: "ofende, desprecia a la propia persona e injuria a nuestros semejantes". Valores sociales que vilipendian, o enaltecen a las personas. Valores cívicos de decencia, dignidad y educación como marcadores de civilidad. La higiene indicó la importancia de realizar: "labores de higiene mental, necesaria para modificar la acción nociva del medio" (Gómez, 1937, p. 279). Respecto a la higiene social, describió el laboratorio de un criminalista:

Los laboratorios eran muy atractivos. El de química, al fondo, de tamaño reducido, estaba casi totalmente ocupado por la mesa sobre la que se veían tubos de ensayo, complicados aparatos de cristal y muchos frascos con reactivos; a un lado de la mesa y había, también armarios con sustancias, un polarímetro, un espectroscopio, campana para gases, conexiones de gas, oxígeno, vacío y agua. Cerca de la oficina de don Benjamín se encontraba el archivo de identificación dactiloscópica, con su estantería de acero, donde se guardaban cientos de miles de fichas. Cuatro o cinco ayudantes sobre la mesa de centro, cotejaban las huellas digitales. En la pared principal estaba colgado el retrato de Vucetich y, en la pared de enfrente, el de Bertillon. El laboratorio de microscopía era también muy importante; un microscopio había, especial, para comparar proyectiles de arma de fuego; otro, que en vez de platina tenía una especia de tabla horizontal, servía para examinar documentos; otro más era parecido al Instituto de Biología. Cerca de este laboratorio estaba el de fotografía, con cuarto oscuro, dispositivos y amplificación y otras cosas. En lugares más alejados había laboratorios, en uno de los cuales, se hacían vaciados de yeso de huellas de neumáticos de automóviles, de pisadas, de llaves... en el archivo estaban y tomos y más tomos de colecciones de delincuentes clasificados según sus actividades: asesinos, ladrones, carteristas, falsificadores, vagos... (Gómez, 1946, p. 355). 
El laboratorio criminalístico, en Don Justo, permitió comprender la delincuencia través del cuerpo (Gómez, 1946). Usó el análisis químico, los archivos dactiloscópico como las fotografías de asesinos, ladrones, carteristas, falsificadores y vagos. Este dispositivo corporal, se basó en las fotografías de Vucetich, (creador de la identificación de huellas dactilares) y, Bertillon; responsable de la tipificación de cuerpos de delincuentes (autor de la antropometría del delincuente).

Gómez (1946) argumentó que la higiene personal, escolar, y social se complementaron con la alimentación:

Exacto - Contestó el maestro- y sin ningún peligro. Para cada alimento se conoce la cantidad de calor que produce durante su combustión química, y también, según el peso del individuo, principalmente, se sabe el número de calorías que necesita para vivir saludablemente. Comer mucho es peligroso; el cuidadoso examen de 200000 personas ha venido a demostrar que la proporción de muertes aumenta progresivamente a medida que se observa un aumento excesivo de peso (p. 320).

La articulación entre lo biológico, lo médico y lo químico formaron un equilibrio corporal entre el peso, la alimentación y la salud. El vivir saludablemente fue una característica visible de civilidad y ciudadanía. En investigaciones previas de Gómez Robleda, se sugirió la intervención del Estado con buena alimentación, ropa adecuada y mobiliario conveniente (Gómez, 1937). Además enfatizó la necesidad de un mobiliario adecuado:

Las posiciones viciadas del cuerpo en la edad escolar, porque los bancos no sean adecuados; porque exista miopía o hipermetropía o astigmatismo; por la costumbre de apoyarse sobre una u otra nalga de preferencia a causa del a dolorimiento de las tuberosidades isquiáticas; porque la escritura sea demasiado inclinada; porque durante la posición de pie se contraiga el hábito de apoyarse más sobre alguno de los dos miembros inferiores con la consiguiente exageración de la respectiva curvatura de la columbra vertebral, etc. Representan otras tantas causas coadyuvantes de las disposiciones naturales del individuo y de la influencia de la edad sobre la génesis de los paramorfismos (Gómez, 1937, pp. 58-59).

Don Justo, consideró la ciencia, la técnica y el trabajo como elementos de construcción de la modernidad y civilidad escolar de los mexicanos (Gómez, 1946). El desarrollo económico y social, en Gómez Robleda, se vinculó con la higiene, y la profesionalización a fin de lograr el progreso social. Estos aspectos establecieron en su posición la modernidad del país y la formación de la ciudadanía. Elementos de un entramado conceptual que tejió una de las piezas del imaginario social del progreso nacional en los años cuarenta y cincuenta en México. La higiene, la ciencia y el progreso penetró en la escuela de Don Justo apuntalando la ciudadanización y modernización nacional. La escuela tuvo como soporte los personajes que circularon en la novela; actuaron de acuerdo con el modelo del buen ciudadano, pensado desde la mirada higienista, social, médica y corporal del momento. Ellos contaron una historia que debemos seguir aclarando, e interpretando, a fin de comprender nuestras nuevas teatralizaciones corporales ciudadanas hoy. 


\section{Conclusiones}

La novela: Don Justo, sirve como una parte de la narrativa socioeducativa en México en la primera mitad del siglo XX, y el papel del cuerpo en la escuela nacionalista. El cuerpo fue expresado en este relato como base de la conformación del ciudadano mexicano. El discurso científico justificó la salud física, moral y social del mexicano. Esta mirada científica marcó la formación de hombres y mujeres a través de su disciplinamiento moral y corporal. Clasificó racialmente la mexicanidad, así como evaluó los cuerpos desde la lógica biotipológica. Don Justo fue una pieza textual que reveló parte del perfil de la formación ciudadana, la civilidad, y la modernidad promovidas por el Estado mexicano. La enseñanza estuvo sostenida del modelo de mexicanidad de la clase media. Esta ciudadanía fue objetivada en los cuerpos de hombres, mujeres, jóvenes e infantes, de manera especial, en los escolares de educación primaria. El maestro fue el formador de los estudiantes, modelo de civilidad en la comunidad y trabajador al servicio de la nación. Don Justo fue un claro ejemplo de un maestro que interpretó la corporalidad ciudadana desde sus características psico-sociales, culturales, políticas e inteligencia. Esta ciudadanía corporal partió del ideal científico, médico, social y económico dominante. El mestizaje corporal imperó sobre lo diverso, y lo particular; tras el intento de borramiento de los rasgos de clase, raza y género. La educación fue proyectada desde una definición de sujetos biométricamente productivos para el Estado. Finalmente, la pedagogía del buen ciudadano, la civilidad, y la modernidad corporal exigen reflexionar profundamente sobre sus implicaciones a la luz de nuevas subjetividades, y de nuevas corporalidades en este siglo XXI.

\section{REFERENCIAS}

Acevedo, R. y López, P. (coords.) (2012). Ciudadanos inesperados. Espacios de formación de la ciudadanía ayer y hoy. México, D.F.: COLMEX/CINVESTAV.

Arredondo, M. A. y González, R. (2014). De la secularización a la laicidad educativa en México. Historia de la Educación. Anuario SAHE, 15(2), 140-167. Recuperado de http://ppct.caicyt.gov.ar/index.php/anuario/article/view/2968

Aréchiga, E. (2007). Educación, propaganda o "dictadura sanitaria». Estrategias discursivas de higiene y salubridad públicas en el México posrevolucionario, 1917-1945. Estudios de historia moderna y contemporánea de México, 56(33), 57-88. https://doi. org/10.22201/iih.24485004e.2007.033.3158

De Certeau, M. (2008). Una política de la lengua. México, D.F.: Universidad Iberoamericana.

De Certeau, M. (2000). La invención de lo cotidiano. 1 Artes de hacer. México, D.F.: Universidad Iberoamericana.

De Certeau, M. (1982). Historias de cuerpos (entrevista). Esprit, Historia y Grafía, 2, 179-190. Recuperado de http://mastor.cl/blog/wp-content/uploads/2015/08/DE-CERTEAU-M-Historia-de-cuerpos-entrevista.pdf 
De la Fuente, J. M. y Heinze, G. (2014). La enseñanza de la psiquiatría en México. Salud Mental, 37(6), 523-553. Disponible en https://www.medigraphic.com/cgi-bin/new/resumen.cgi?IDARTICULO $=57073$

De la Peza, M. y Corona, S. (2000). Educación cívica y cultura política. En, Y. Corona (coord.), Infancia, legislación y política (pp. 69-78). México, D.F.: UAM. Recuperado de https://programainfancia.uam.mx/pdf/publicaciones/infancia_legis/infancia.pdf

Domínguez, H. (mayo, 2011). Cine mexicano entre 1940-1970. Cultura y vida cotidiana 1940-1970. Recuperado de https://portalacademico.cch.unam.mx/repositorio-desitios/historico-social/historia-de-mexico-2/HM2-3CultPortal/Cine1940.pdf

Enríquez, G. A. y Cruz, J. (2020). Contornos y límites corporales del hombre medio en México (1930-1960). Revista Corpo-grafias: Estudios críticos de y desde los cuerpos, 7(7), 55-67. https://doi.org/10.14483/25909398.15505

Enríquez, G. A y Sandoval, F. R. (2018). La construcción del hombre medio en José Gómez Robleda: biotipología y masculinidad en México (1940-1960). Mitologías hoy, 18, 187-204. Recuperado de https://revistes.uab.cat/mitologias/article/view/v18-gutierrez-sandoval

Faulhaber, J. (2003). Ada D’Aloja (1900-2004). Anales de Antropología, 37(1), 325328. Recuperado de http://www.revistas.unam.mx/index.php/antropologia/article/ view/16816

Fast, J. (1988). El lenguaje del cuerpo. México, D.F.: Kairós Colofón.

Foucault, M. (2007). Introducción. El nacimiento de la biopolítica. México, D.F.: FCE.

Foucault, M. (1980). El discurso del poder. México, D.F.: Folios ediciones.

Gómez, M. L. y García, O. (2018). Adaptaciones cinematográficas de la obra corazón diario de un niño (Edmundo D’Amicis,1886). En. M. Alcántara, M. García y F. Sánchez (Coord.). Historia y patrimonio cultural. Memoria del $56^{\circ}$ Congreso Internacional de Americanistas (pp.1577-1591). Salamanca: Ediciones Universidad de Salamanca. Recuperado de http://ri.uaemex.mx/bitstream/handle/20.500.11799/98961/7.3.61.\%20 56\%20ICA\%20Historia\%20Lizcano.pdf?sequence=1\&isAllowed=y

Gómez, J. (1961). Estudio biotipológico de los Otomies. México, D.F.: UNAM.

Gómez, J. (1959). La familia y la casa. México, D.F.: UNAM.

Gómez, J. (1948). La imagen del mexicano. México, D.F.: SEP.

Gómez, J. (1947). Biotipología. México, D.F.: Talleres gráficos de la nación.

Gómez, J. (1946). Don Justo. México, D.F.: SEP.

Gómez, J. (1943). Pescadores y campesinos tarascos. México, D.F.: SEP.

Gómez, J. (1940). Deportistas. México, D.F.: SEP.

Gómez, J. (1937). Características biológicas de los escolares proletarios. México, D.F.: SEP. 
González, M. O. (2009). La ciudad en el cine mexicano: (1940-1980). Cuatro décadas de nota roja y sociodrama nacional. Nómadas. Revista de Ciencias Sociales y Jurídicas, 21(1), 421-438. Disponible en https://revistas.ucm.es/index.php/NOMA/article/view/ NOMA0909140421A

Granjas, J. (2011). El lenguaje escolar de la desigualdad en el umbral de la "primera oleada de expansión» de la enseñanza obligatoria. México en la segunda mitad del siglo XX. Revista Mexicana de Investigación Educativa, 16(48), 17-42. Disponible en https://www.comie.org.mx/revista/v2018/rmie/index.php/nrmie/article/view/359

Gudiño-Cejudo, M. R., Magaña-Valladares, L. y Hernández-Ávila, M. (2013). La Escuela de Salud Pública de México: su fundación y primera época, 1922-1945. Salud Pública de México, 55(1), 81-91. Disponible en https://www.saludpublica.mx/index.php/spm/ article/view/7191

Guzmán, A. (2008). Nuestro cuerpo hoy. En, E. Muñiz (coord.). Registros corporales. La historia cultural del cuerpo humano (pp. 437-462). México, D.F.: UAM-Azcapotzalco.

Illades, C. y Suárez, R.E. (2012). México como problema: esbozo de una historia intelectual. México, D.F.: UAM-I/ UAM-C/Siglo XXI. Disponible en http://ilitia.cua.uam. mx:8080/jspui/handle/123456789/160

Lazarín, F. (1996). Educación para las ciudades. Las políticas educativas 1940-1982. Revista Mexicana de Investigación Educativa, 1(1), 166-180. Disponible en https:// www.comie.org.mx/revista/v2018/rmie/index.php/nrmie/article/view/1089

Le Breton, D. (1995). Antropología del cuerpo y modernidad. Buenos Aires: Nueva Visión.

Loaeza, S. (2013a). La reforma política de Manuel Ávila Camacho. Historia de México, 63(1), 252-358. Disponible en https://historiamexicana.colmex.mx/index.php/RHM/ article/view/160

Loaeza, S. (2013b). Dos hipótesis sobre el presidencialismo autoritario. Revista de Ciencias Política y Sociales, 58(218), 53-72. Disponible en http://www.revistas.unam.mx/ index.php/rmcpys/article/view/42660

López, S. (2009). Historia social del cuerpo humano en México. Mundo siglo XXI, 6, 39-48. Recuperado de https://www.mundosigloxxi.ipn.mx/pdf/v04/16/03.pdf

Matos, E. (2001). La antropología en México. Revista Ciencia, 52(3), 36-43. Recuperado de https://revistaciencia.amc.edu.mx/images/revista/51_3/antropologia.mexico.pdf

Melchor, Z. (2018). Eugenesia y salud pública en México y Jalisco revolucionarios. Letras históricas, (18), 93-115. http://dx.doi.org/10.31836/1h.18.6341

Medina, L. (1974). Origen y circunstancia de la idea de unidad nacional. Foro Internacional, 14, 3(55), 265-290. Disponible en https://forointernacional.colmex.mx/index. $\mathrm{php} / \mathrm{fi} / \mathrm{article} / \mathrm{view} / 652$

Muñiz, E. (2002). Cuerpo, representación y poder. México en los albores de la reconstrucción nacional, 1920-1934. México, D.F.: UAM-A/Miguel Ángel Porrúa. 
Olvera, M. (2016). Los aportes de Lucio Mendieta y Núñez a la institucionalización de la sociología en México (1939-1951). Tempo Social, 28(3), 77-94. https://doi. org/10.11606/0103-2070.ts.2016.111594

Ornelas, C. (1995). El sistema educativo mexicano. La transición de fin de siglo. México, D.F.: FCE.

Ortiz-Cirilo, A. (2015). Laicidad y reformas educativas en México (1917-1992). México, D.F.: UNAM-IIJ. Disponible en http://catedra-laicidad.unam.mx/detalle-cultura-laica/79/Laicidad-y-reformas-educativas-en-M\%C3\%A9xico-\%281917-1992\%29

Piccato, P. (2012). Epílogo. De la ciudadanía a los ciudadanos: notas sobre la contin- gencia en la historia política. En, A. Acevedo y P. López (coord.), Ciudadanos inesperados: espacios de formación de la ciudadanía ayer y hoy (pp. 315-336). México, D.F.: COLMEX/CINVESTAV.

Quiroz, A., Gómez R. J. y Argüelles B. (1939). Tendencia y ritmo de la criminalidad en México. México, D.F.: SEP.

Rangel, A. (2006). La educación rural mexicana y la educación fundamental en el inicio del CREFAL. Revista Interamericana de Educación de Adultos, 28(2), 169-176. Recuperado de https:/www.crefal.org/rieda/images/rieda-2006-2/contrapunto3.pdf

Reggiani, A. H. (2019). La eugenesia en América Latina. México, D.F.: El Colegio de México. Recuperado de https://libros.colmex.mx/wp-content/plugins/documentos/descargas/HM_EUGENESIA_B.pdf

Reyes, A. (2005). Sentido del ser social. Carilla moral. Cartilla moral. Conciencia del entorno. México, D.F.: Universidad Autónoma de Nuevo León (Lecturas Universitarias). Recuperado de http://cdigital.dgb.uanl.mx/la/1080129436/1080129436_MA.PDF

Saade, M. (2004). ¿Quiénes deben procrear? Los médicos eugenistas bajo el signo social (México, 1931-1940). Cuicuilco, 11(31), 45-80. Disponible en https://revistas.inah. gob.mx/index.php/cuicuilco/article/view/452

Sosenski, S. y López, R. (2015). La construcción de la felicidad y la convivencia familiar en México: los anuncios publicitarios en la prensa gráfica (1930-1970). Secuencias. Revista de historia y ciencias sociales, 92, 193-225. Disponible en http://secuencia. mora.edu.mx/index.php/Secuencia/article/view/1339

Stern, A. (2002). Madres conscientes y niños normales: la eugenesia y el nacionalismo en el México posrevolucionario, 1920-1940. En, L. Cházaro (ed.), Medicina, ciencia y sociedad en México, siglo XI (pp. 293-336). México, D.F.: El Colegio de Michoacán/ Universidad Michoacana de San Nicolás de Hidalgo.

Stern, A. (2000). Mestizofilia, biotipología y eugenesia en México posrevolucionario: hacia una historia de la ciencia y el estado, 1920-1960. Relaciones. Estudios de historia y sociedad, 21(81), 59-91. Disponible en http://www.revistarelaciones.com/index.php/ relaciones/index

Suárez, L. (2005). Eugenesia y racismo en México. México, D.F.: UNAM. Disponible en http://www.librosoa.unam.mx/handle/123456789/2225 
Suárez, L. (1999). La influencia de la sociedad eugénica mexicana en la educación y en la medicina social. Asclepio, 52, 51-84. Recuperado de http://asclepio.revistas.csic.es/ index.php/asclepio/article/viewFile/310/306

Suárez, L. y Ruíz, R. (2001). Eugenesia y medicina social en el México posrevolucionario. Ciencias, 60, 80-86. Recuperado de http://www.revistas.unam.mx/index.php/cns/article/view/11753

Tuñón, J. (1994). La silueta de un vacío: Imágenes fílmicas de la familia mexicana en los años cuarenta. Filmhistoria, (2), 137-147. Disponible en https://raco.cat/index.php/ FilmhistoriaOnline/article/view/226242

Vejar, O. (1944). Hacia una escuela de unidad nacional. Discursos. México, D.F.: SEP.

Vigarello, G. (2005). Historia de la belleza. El cuerpo y el arte de embellecer desde el renacimiento hasta nuestros días. Buenos Aires: Nueva Visión.

Gustavo Adolfo Enríquez Gutiérrez es Profesor-Investigador de Tiempo Completo de la Universidad Pedagógica Nacional-Morelos (México). Integrante del Sistema Nacional de Investigadores. Línea de investigación: Narrativas, políticas y procesos sobre la diversidad. Doctor en Educación (UAEM-ICE). https://orcid.org/0000-0002-2099-9072 